\title{
JUDICIALIZACIÓN DEL CONFLICTO COLECTIVO Y EL ROL DEL JUEZ EN SU SOLUCIÓN*
}

\section{JUDICIALIZATION OF THE COLLECTIVE CONFLICT AND THE ROLE OF THE JUDGE IN THEIR SOLUTION}

\author{
PATRICIA FUENZALIDA MARTÍNEZ**
}

\begin{abstract}
RESUMEN: El presente trabajo analiza el rol del Juez en el conflicto colectivo, destacando sus principales dificultades y proponiendo un esquema, bajo el cual, mediante el apego irrestricto al derecho y los principios que rigen su ética profesional, el Juez puede intervenir en la solución de tales conflictos de un modo que no sólo cumpla con la carga que la Constitución le impone, sino que colabore en la búsqueda de la justicia y la paz social.
\end{abstract}

Palabras clave: conflicto colectivo, judicialización, principios, debido proceso.

ABSTRACT: This paper analyzes the role of the Judge in the labor collective conflicts. It emphasizes its main difficulties and proposes a model of judicial good practices based in a complete adherence to the Law and professional ethics. Under it, the judge might intervene in the solution of such conflicts in a way that not only fulfills her Constitutional obligations but also collaborates in the search for justice and social peace.

Key words: collective conflicts, judicialization, principles, due process.

\section{INTRODUCCIÓN}

Probablemente, si le presentaremos a cualquier persona, con formación jurídica o no, la frase "conflicto colectivo" y luego le preguntásemos qué imágenes o ideas le evoca, una respuesta que se repetiría sería la de los directamente involucrados en el conflicto, esto es, la imagen de los trabajadores sindicalizados o de la empresa con los trabajadores en su entrada o con lienzos alusivos a la movilización; quizás pensaría en los fines o intereses de cada uno durante la negociación, en los medios a qué pueden recurrir para conseguirlos, y en cómo aquello afectará su vida o actividades habituales. Sin embargo, parece menos probable que, ante este tipo de situaciones, tan estrechamente vinculadas con la realidad política y económica del país, se

\footnotetext{
* El presente trabajo corresponde a un compendio de la presentación efectuada en la $4^{\circ}$ Sesión del Seminario sobre reforma laboral efectuado en la Facultad de Derecho de la Universidad de Chile entre el 14 de julio y el 05 de agosto de 2015; así como de aquella comunicación presentada en el $4^{\circ}$ Panel de las XXII Jornadas nacionales de la sociedad chilena de derecho del trabajo y la seguridad social, celebradas en la Facultad de Derecho de la Universidad de Chile entre los días 21 y 23 de octubre de 2015.

**Abogada; Licenciada en Ciencias Jurídicas de la Pontificia Universidad Católica de Chile; Magíster en Derecho del Trabajo por la Universidad Adolfo Ibáñez; Máster en Tutela de Derechos Fundamentales: La Protección Jurisdiccional en Materia de Género y Menores, programa impartido por la Universidad de Jaén, en colaboración con el Instituto de Estudios Judiciales, entre otros; Juez Titular del Segundo Juzgado de Letras del Trabajo de Santiago; profesora de Derecho del Trabajo y de la Seguridad Social. Contacto: pfuenzalida@pjud.cl
} 
piense, al menos de inmediato, en el juez, quien bien puede aparecer con posterioridad, pero, siempre como un operador de segundo orden en la evolución y resolución del conflicto, más bien relacionado con los aspectos formales del proceso de negociación colectiva, que con su desarrollo y concreción en contrato colectivo.

Pues bien, en las páginas siguientes, intentaremos defender la idea de que el juez sí tiene un rol importante en este tipo de conflictos, cuya particular naturaleza no disminuye para nada, si es que incluso no aumenta, el crédito que la sociedad posee en contra de este funcionario encargado, precisamente, de resolver conflictos de relevancia jurídica de manera independiente, imparcial y mediante el pronunciamiento de decisiones debidamente fundadas, no en su mero parecer, sino en las probanzas de las partes y el contenido de las normas y principios aplicables al caso. Más aún, atendida la cantidad de personas involucradas, directa e indirectamente, en un conflicto de tipo colectivo y la relevancia de los temas discutidos, muchos de ellos íntimamente relacionados con la eficacia y vigencia de una serie de derechos fundamentales, su intervención en este tipo de cuestiones puede resultar aún más útil, en términos de aporte a la justicia, la paz social, y la promoción del bien común, lo que puede decirse, por ejemplo, respecto de un conflicto entre particulares de carácter meramente patrimonial.

Es así que, el juez no puede ser un mero espectador del conflicto colectivo, y su participación en aquel no puede limitarse a la verificación de una secuencia de ritualidades o etapas procesales, sino que, sobre todo en este tipo de asuntos, debe cumplir su función con la mayor rigurosidad exigible, considerando tanto las normas que rigen su actuar, como las exigencias que derivan de su propia ética profesional. Dado que su compromiso -o falta de aquel- con tales aspectos, puede incidir de manera importante en el desarrollo y desenlace, tanto del conflicto colectivo actual en que debe emitir su pronunciamiento como en otros futuros, pudiendo extenderse el alcance de su labor, incluso, a la esfera extrajudicial y la resolución de tales conflictos a través de medios alternativos al proceso.

Cuestiones todas, que resultan tan válidas en el escenario actual, marcado por las normas vigentes sobre derecho laboral colectivo, como en aquel nuevo escenario que surja como resultado de las modificaciones que sean introducidas a nuestro ordenamiento, luego de concluida la discusión referida al Proyecto de ley que moderniza el sistema de relaciones laborales, actualmente en tramitación ${ }^{1}$.

\footnotetext{
${ }^{1}$ Proyecto de ley que moderniza el sistema de relaciones laborales, introduciendo modificaciones al Código del Trabajo, enviado por la Presidenta de la República a la Cámara de Diputados con fecha 29 de diciembre de 2014, mediante Mensaje $\mathrm{N}^{\circ} 1055-362$.
} 


\section{EL CONFLICTO COLECTIVO COMO CONFLICTO JURÍDICO}

Si entendemos por conflicto colectivo aquel que es producto de la negociación colectiva y del ejercicio de su principal herramienta, la huelga ${ }^{2}$, sin perjuicio de la posibilidad de extenderlo a las distintas cuestiones que se puedan suscitar en sus etapas previas, desde la constitución del respectivo sindicato y hasta la interpretación y aplicación de los acuerdos adoptados como producto de dicha negociación, es claro que nos encontramos frente a una problemática de contenido jurídico.

En efecto, no se trata simplemente de un mero conflicto de intereses, sino que de uno fuertemente reglado por el derecho, en que las partes pretenden y resisten, respectivamente, la asignación de beneficios señalados igualmente con mayor o menor precisión en normas jurídicas; conflicto que, en definitiva, dice relación con el ejercicio de una serie de derechos fundamentales, entre ellos, el derecho a sindicación y la libertad sindical, por parte de los trabajadores que en tal calidad inician el proceso, y el derecho a la propiedad y a desarrollar cualquier actividad económica, por parte del empleador, todo ello sin perjuicio de otros derechos fundamentales de terceros que puedan verse afectados a consecuencia de la negociación, como ocurre, por ejemplo, durante el curso de una huelga declarada en empresas que prestan servicios básicos para la población, como puede ocurrir con aquellas que ofrecen servicios médicos o educacionales.

De este modo, podemos encuadrar al conflicto colectivo dentro de las normas referidas a la libertad sindical, derecho fundamental consagrado y regulado constitucional y legalmente, lo que supone que aquellas cuestiones que origine su ejercicio corresponden a conflictos de relevancia jurídica, cuya resolución ha sido entregada por la Constitución Política al Poder Judicial, el que debe conocer y resolver de tales conflictos siempre de conformidad a la Constitución y las leyes, respetando el principio de juridicidad ${ }^{3}$, según manda el artículo $6^{\circ}$ de la Constitución Política de la República.

Sin embargo, es igualmente evidente que el conflicto colectivo tiene componentes que exceden del meramente jurídico y que deben ser considerados al momento de analizar el modo en que éste se desarrolla en la realidad. En tal sentido, debemos considerar que si bien se trata de conflictos jurídicos, son conflictos con un importantísimo contenido económico, más aún dado que el propio legislador al definir la negociación colectiva, como hace el artículo 303 del Código del Trabajo, la circunscribe a la discusión sobre prestaciones económicas o, en su mayoría, avaluables en dinero, de modo que serán relevantes en la discusión las expectativas de

\footnotetext{
2 SUPIOT (2008) p. 95.

${ }^{3}$ Para un análisis detallado acerca de la vigencia del principio de juridicidad respecto de la actividad jurisdiccional desarrollada por los distintos Tribunales que conforman el Poder Judicial y los alcances de aquel, ver: Ruay Sáez, Francisco, "Análisis crítico de las potestades atípicas del juez laboral ante el principio de juridicidad”, en Revista chilena de derecho del trabajo y de la seguridad social, Facultad de Derecho de la Universidad de Chile, Vol. 5, N 9, 2014, p. 83-105.
} 
mejora económica que los trabajadores involucrados se puedan formar a partir tanto de los resultados particulares de la empresa como de aquellos producidos de manera más global en el país, resultados que a su vez pueden, dependiendo el tamaño o importancia de la empresa, verse a su vez afectados por el resultado de la negociación de las partes, pero, la negociación colectiva no sólo centra el debate en los aspectos económicos, que podrían ser de sencilla discusión, sino que uno de los aspectos que la complejiza son las asignaciones de poder e información que se producen entre las partes durante el proceso, dado que quienes se enfrentan en este tipo de negociaciones, como ha destacado el Tribunal Constitucional Español, se encuentran en una constante "posición dialéctica de contrapoder... y que la defensa de sus objetivos no se basa en fórmulas de composición de intereses o de colaboración, sino de autodefensa" 4 . Por otra parte, como hemos indicado previamente, los resultados de este conflicto, puede incidir también en cuestiones que exceden de la sola situación contractual de las partes involucradas, teniendo la potencialidad de afectar a la economía nacional y, por cierto, que al propio mercado laboral.

A fin de graficar las implicancias extra jurídicas del conflicto colectivo, no sólo en sus efectos, sino también en cuanto al modo en que las distintas visiones u orientaciones políticas y económicas de las partes impregnan sus interpretaciones acerca de las normas jurídicas que regulan la materia, podemos citar un análisis sobre la evolución del conflicto colectivo durante el siglo XX, efectuado por el Profesor William Thayer Arteaga, quien destaca una serie de aspectos de estos conflictos que han ido cambiando en el tiempo, asociados a cambios culturales e incluso ciertos eventos históricos que han afectado las conductas desplegadas por quienes participan del conflicto, en particular, por los sindicatos. Sostiene, por ejemplo, que estos se han vuelto más pacíficos, más reglados, informados, con peticiones y ofertas más fundamentadas; también destaca cuestiones tales como que se ha ido adquiriendo mayor conciencia acerca de la necesidad de no ver comprometida la estabilidad en el trabajo por la pérdida de la competitividad de la empresa, y preocupación acerca del deber moral, la necesidad política y la conveniencia económica de mantener buenas relaciones humanas dentro de la profesión, el país y la comunidad internacional; a la vez que el conflicto ha pasado a tener un cariz más participativo, tendiendo a dejar atrás la lógica de la lucha de clases, sin perjuicio de añadir que, precisamente, el sindicato actual "aún no asimila las ventajas de la participación, y se considera debilitado por la pérdida del espiritu de lucha de clases, que aún no se internaliza como un sentido de "lucha por la justicia social""

Pero, no sólo son las partes directamente involucradas en el conflicto quienes incorporan en su análisis y en sus decisiones criterios que exceden de los argumentos fundados en las normas y principios que rigen la materia, sino que este actuar se advierte también de parte de ciertos sectores de la academia, cuyas afirmaciones en ocasiones incluyen una serie de afirmaciones de difícil verificación científica.

\footnotetext{
${ }^{4}$ Como se destaca en los considerandos contenidos en el capítulo "II Fundamentos Jurídicos" de la Sentencia 134/1994 de 9 de mayo de 1994, dictada por la Segunda Sala del Tribunal Constitucional Español, disponible en http://hj.tribunalconstitucional.es/HJ/ca-ES/Resolucion/Show/SENTENCIA/1994/134.

5 THAYER (2010), p. 208
} 
Lo anterior, nuevamente, es válido tanto respecto del escenario ofrecido por nuestro actual Derecho Colectivo del Trabajo, como de la discusión motivada por el Proyecto de Reforma de Ley presentado por el Ejecutivo en diciembre pasado. Proyecto que ha motivado un intenso debate que se ha realizado en paralelo tanto en el Congreso Nacional, como en las aulas universitarias y a través de los medios de comunicación. Es así que hemos podido ver, cómo durante el curso de todo este año, las páginas de distintos diarios y medios de comunicación social han incluido permanentes comentarios y opiniones acerca del Proyecto y sus posibles alcances, asimismo, todas aquellas negociaciones colectivas que han tenido alguna connotación social, principalmente huelgas que por su extensión temporal o por el tipo de servicios prestado por los trabajadores afectos a ella han causado molestias a importantes sectores de la ciudadanía ${ }^{6}$, han sido objeto de comentarios y notas de prensa que las destacan como ejemplo de la conveniencia o no de aprobar el Proyecto en sus términos actuales, comparando su desarrollo con aquel que habrían tenido en caso de haberse producido luego de aprobado el Proyecto.

De entre todas aquellas opiniones emanadas tanto de periodistas, analistas y operadores políticos, parlamentarios y miembros del ejecutivo, nos encontramos con algunas afirmaciones como las siguientes:

"Intervenciones legislativas como las de la reforma... sólo cobran sentido bajo aquellas ideologías que ignoran el rol del mercado en la retribución del trabajo, sustituyéndolo por relaciones de fuerza o poder";

"Estamos en presencia de una "guerra santa" en la que los defensores a ultranza del modelo... buscan alterar lo menos posible los estrechos límites de esta prisión normativa, para pretender convencer a sindicatos ingenuos de que se están rompiendo las cadenas";

"El problema es que (la reforma) solo atiende la perspectiva de los buelguistas, sin embargo no considera al resto de trabajadores... Aqui está en juego la propia subsistencia de la empresa dependiendo de qué tan exigente sean las demandas de los trabajadores";

"Cómo defender un proyecto que amenaza con castigar a los dirigentes sindicales que abusen de sus derechos sindicales? $?^{10}$ "

\footnotetext{
${ }^{6}$ A este respecto, es posible recordar las notas de prensa que han acompañado las huelgas de los trabajadores de empresas de transportes de valores, Prosegur y Brinks; o a las distintas movilizaciones y huelgas efectuadas por conductores de buses de la locomoción colectiva durante el año; o los análisis que se efectuaron en relación a la posibilidad de que los trabajadores del Banco del Estado hubieren iniciado una huelga; lo que también ha ocurrido respecto de aquellas movilizaciones que, fuera del sistema de negociación colectiva, han realizado funcionarios de distintas reparticiones públicas, tales como el Servicio de Registro Civil e Identificación.

7 MARTÍNEZ (2015): “Reforma laboral, la peor de todas”, El Libero. Disponible en: http://ellibero.cl/ideaslibres/reforma-laboral-la-peor-de-todas/.

8 CAAMAÑO (2015): "Los nuevos carceleros de la libertad sindical", El Mostrador. Disponible en: http://www.elmostrador.cl/noticias/opinion/2015/07/31/los-nuevos-carceleros-de-la-libertad-sindical/.

${ }^{9}$ PALAVECINO (2015): "Mayor protagonismo de la dirección del trabajo trae el riesgo que el conflicto colectivo se politice", Estrategia on line. Disponible en: http://www.estrategia.cl/noticias/detalle/ultimo-minutoportada/110993/mayor-protagonismo-de-la-direccion-del-trabajo-trae-el-riesgo-que-el-conflicto-colectivo-sepolitice.

10 UGARTE (2015): “El senador Lagos Weber y la OIT 'a la carta”, El Mostrador. Disponible en: http://www.elmostrador.cl/noticias/opinion/2015/07/07/el-senador-lagos-weber-y-la-oit-a-la-carta/.
} 
Todas estas frases tienen dos cosas en común. La primera es que todas ellas reflejan uno de los mayores desafíos que supone el conflicto colectivo para el mundo del derecho, cual es, que dado su estrecho vínculo con la realidad del mundo del trabajo y la economía, presenta un enorme potencial para combinar, en un mismo debate, argumentos jurídicos, de contenido lógico y racional, con otros que más bien apuntan a animar las pasiones, deseos y temores de los individuos y las sociedades en que este se produce. En efecto, no es extraño encontrar en este tipo de discusiones, sean teóricas o referidas a un conflicto en particular, una serie de caricaturas y de imágenes preconcebidas en relación a los intereses y motivaciones de cada uno de los involucrados, expresadas en afirmaciones que pretenden mostrar al empleador como un personaje abusivo, que busca instalar jornadas extenuantes a cambio de pagos mínimos, añorando el trabajo esclavo, o aquellas que muestran al trabajador como un personaje que exige altos sueldos y beneficios por dedicarse a dormir o a leer el diario durante toda la jornada, y es así que, entre párrafos de debate jurídico vemos como con frecuencia se deslizan conceptos referidos a lucha de clases y otros similares, que más nos recuerdan personajes y situaciones literarias o de televisión, que a principios, fines o normas jurídicas.

Por cierto que este no es un fenómeno nuevo, sino una característica más bien permanente del conflicto colectivo, en efecto, hace ya casi 20 años atrás, el Profesor Emilio Morgado iniciaba un estudio sobre el tema con la siguiente prevención: "Sin duda, lo concerniente a la negociación colectiva es un tema apasionante, en el doble sentido del interés que concita y de las perfiladas posiciones que suelen asumir sus analistas. A veces, ese apasionamiento conduce a concepciones fundadas en prejuicios y sospechas, que favorecen enfrentamientos en que el dogmatismo desfigura la realidad y dificulta la búsqueda serena de consensos respecto de un tema de tan vital importancia" 11.

Ahora bien, sin perjuicio de la permanencia en el tiempo de este fenómeno, quizás lo que más nos deba preocupar acerca del uso de estas caricaturas y prejuicios, es que aquellas no sólo han sido empleadas por los actores directos del conflicto, dirigentes de organizaciones sindicales o empresariales, ni por los operadores políticos, sino que también por parte de la academia nacional. En efecto, la segunda característica que las frases antes citadas tenían en común, es que todas corresponden a académicos de importantes universidades nacionales.

Y, entonces, si esa es la realidad del conflicto colectivo y la actual discusión en relación al Proyecto que pretende mejorar y modernizar el contexto en que se produce la negociación, podemos formularnos una serie de preguntas de la máxima relevancia, especialmente, al considerar el modo en que se trate este conflicto y las soluciones que se propongan. Entre otras, podemos mencionar las siguientes: ¿significa lo expuesto que este conflicto no puede ser realmente caracterizado como uno de tipo jurídico o que su carácter jurídico debe ceder ante los aparentemente aplastantes argumentos de la política y la economía?, ¿es acaso que nuestra aproximación a este conflicto debe realizarse desde fuera del mundo del derecho y con herramientas metodológicas ajenas a nuestra disciplina?, ¿es posible conjugar posturas como las antes descritas con los clásicos mandatos del derecho, tales como vivir honestamente, no hacer daño a nadie y dar a cada uno lo que le corresponde?, ¿qué espacio hay para la equidad, la paz, la razón, y en definitiva, para la justicia, cuando son precisamente aquellos que deberían

${ }^{11}$ MORGADO (1998), p. 162. 
aportar argumentos que consideren esos mandatos, quienes plantean el debate laboral en términos excluyentes o de suma cero?, ¿cómo buscar una solución justa al conflicto, sea en la etapa de la creación de la norma o en su aplicación, cuando lo pretendido en realidad parece ser más bien el anular a la contraparte?.

Es así que, si bien podemos caracterizar al conflicto colectivo, en particular a la negociación colectiva, tanto como una institución jurídico laboral como una institución política social y económica, además de destacar su carácter de instrumento generados de participación social $^{12}$, no podemos perder de vista el preponderante aspecto jurídico de la institución. Si queremos sostener con propiedad que formamos parte de un Estado de Derecho, y dado que nuestro ordenamiento regula tanto los fines de la negociación colectiva, como los mecanismos o causes a través de los cuales esta debe desarrollarse, parece necesario que el desarrollo del conflicto colectivo, y en particular el actuar de las partes, se apegue a los propios derechos y obligaciones previstos en nuestro sistema jurídico, más allá de los deseos, intereses o aspiraciones de los operadores del sistema.

En este punto no podemos dejar de reiterar que si el juez, llamado a declarar la correcta interpretación y contenido último de la norma, elige lo deseable o lo óptimo por sobre aquello previsto por la legislación, podría quizás llegar a una solución más justa en el caso concreto, pero, ese aparente beneficio se conseguiría bajo el riesgo de restar eficacia y vigencia a normas que, pese a su mejor o peor calidad, han sido dictadas, de conformidad al principio democrático, por el órgano electo por la ciudadanía y llamado por la Constitución a desarrollar tal función.

En estas circunstancias, el Juez, en su calidad de tercero independiente, imparcial y garante del Estado de Derecho y de la vigencia y eficacia de las normas que este se ha dado, puede y debe, de conformidad a los mandatos que le impone la Constitución Política, encausar el conflicto colectivo hacia los márgenes del Derecho, pudiendo dictar, mediante el pronunciamiento de decisiones consistentes y debidamente fundadas, pautas claras que definan cuál es el actuar que el bien común, la justicia y la paz social, exigen y permiten de las partes. Lo anterior, salvo que como sociedad estemos dispuestos a dejar el conflicto entregado simplemente a la ley del más fuerte y olvidar que nuestra organización jurídica se sustenta, precisamente, en la renuncia del uso de la fuerza de parte de los ciudadanos y la radicación de su ejercicio de manera legítima exclusivamente en el Estado.

\section{EL ROL DEL JUEZ EN EL PROCESO JUDICIAL}

A fin de precisar cuál debe ser el rol que le corresponde asumir al Juez en el conflicto colectivo, una vez judicializado, debemos necesariamente recordar cuál es el rol que el juez está llamado a cumplir en todo conflicto judicial y qué es, en definitiva, lo que define a la función, y esto es, conocer y resolver las causas que se le presentaren de manera independiente, imparcial,

12 Ibíd., pp. 162 y 163. 
y de conformidad a Derecho, vale decir, el juez no es un funcionario que goce de facultades para decidir cada cuestión según sus gustos o intereses personales, ni para perseguir su propio programa o ideal de justicia, o para subrogar la actuación de una u otra parte en el proceso, sino que existe única y exclusivamente para garantizar la vigencia del derecho mediante la ratificación diaria de su eficacia en la vida social, siendo el garante de la vigencia de los derechos fundamentales ${ }^{13}$. Máxime que, como destaca la doctrina, cuando un Juez interviene en un asunto no lo hace en nombre propio sino en tanto representante de la soberanía nacional o en tanto órgano del Estado ${ }^{14-15}$.

Ahora bien, por cierto, que cuando decimos que el Juez debe ajustar su actuar o sus decisiones a los dictados del Derecho, debe entenderse Derecho no como sinónimo únicamente de ley, sino como concepto comprensivo de las distintas fuentes que componen el ordenamiento, entendiendo por aquello tanto la Constitución, las leyes, los convenios internacionales, la jurisprudencia, la doctrina, y los principios, tanto los propios del Derecho del Trabajo, como los generales. De modo que el Juez debe aplicar y velar por la vigencia del Derecho en su integridad, ya que será precisamente el juego de todas estas fuentes, de conformidad a las reglas de interpretación aplicables en su caso, el que nos proveerá de la resolución acertada en cada caso, la que debe ser extraída de dichas fuentes y no de las aspiraciones o deseos de los operadores, por legítimas que estas puedan parecer.

Lo anterior, en nuestra especialidad, supone que el juez continuamente deberá buscar un equilibrio, entre la aplicación de las normas y principios propiamente laborales, centrada más bien en la protección de una de las partes contratantes ${ }^{16}$, con aquellos principios o garantías generales del Derecho que buscan la igual protección de ambas partes, como son la igualdad ante la ley, el debido proceso y la buena fe. Sin embargo, dicha dicotomía es más bien aparente, ya que en definitiva, tanto las normas que brindan mayor protección a una parte, como aquellas que parecen instar por una igualdad absoluta en términos procesales, apuntan al mismo fin, cuál es, hacer realidad el derecho a la igual protección en el ejercicio de los derechos que la Constitución garantiza a todos los ciudadanos, tanto en la materialidad de la relación laboral, como luego durante el curso del proceso judicial. Es precisamente en razón de aquello

\footnotetext{
${ }^{13}$ Andrés Ibáñez, Perfecto, en: Cultura constitucional de la jurisdicción, Ed. Siglo del Hombre, Bogotá, 2011, pp. 82 y 83, destaca que el rol del juez como garante de la ley, puede exigir tanto la adopción de decisiones contramayoritarias, así como también requiere del juez una lectura crítica de las leyes a fin de ejercer y del ejercicio de un control de legalidad de las actuaciones político-administrativo, a fin de respetar el marco constitucional al que debe circunscribir su actuación.

${ }^{14}$ RUAY SÁEZ (2014) p. 87.

${ }^{15}$ En similar sentido se pronuncia el profesor Eduardo Soto Kloss, quien al explicar qué debe entenderse por Juez, destaca principalmente dos aspectos, que se trata de un órgano del Estado, atribuido por la Constitución de la función jurisdiccional, y que el ejercicio de dicha función importa decidir las contiendas de modo independiente e imparcial. En Soto Kloss, Eduardo, Derecho administrativo, bases fundamentales, Tomo II, Ed. Jurídica de Chile, 1996 , p. 39.

${ }^{16}$ Siendo abundantes las menciones a los principios que informan la especialidad en las sentencias que dictan tanto los Tribunales de instancia como los Superiores, en particular, al principio pro operario o protector, como aquel que debe guiar la interpretación que realice el juez, como ocurre por ejemplo con la sentencia de reemplazo dictada por la Excma. Corte Suprema con fecha 10 de junio de 2014, en el Recurso de Unificación de Jurisprudencia $\mathrm{N}^{\circ}$ 10.139-2013, cuyo considerando octavo indica que las normas traídas al proceso deben ser analizadas "...bajo el prisma interpretativo propio del Derecho Laboral que permite a los jueces la asignación de sentido de sus disposiciones conforme el criterio pro operario...”.
} 
que las normas de carácter protector, serán preferentemente aquellas referidas al fondo del asunto, la legislación laboral propiamente tal, las que lejos de establecer alguna preferencia o ventaja indebida hacia una de las partes, pretenden nivelar las condiciones en que la relación se desarrolla producto, principalmente, de las diferencias que en términos de poder e información, entre otros, se constatan entre empleador y trabajador; en tanto que en materia procedimental, la regla general es que el legislador tampoco persiga una igualdad meramente formal, sino que busque crear las condiciones que permitan a ambas partes acceder en condiciones similares al proceso, lo que no es sinónimo de establecer una suerte de igualdad de armas meramente formal, ya que como lo demuestran ciertas instituciones procesales modernas, como es la carga dinámica de la prueba, en ocasiones para lograr, precisamente aquella igualdad se requiere establecer determinadas cargas a una u otra parte. Un ejemplo de aquello es la regla prevista en el artículo $454 \mathrm{~N}^{\circ} 1$ del Código del Trabajo, que dispone que en los casos de despido sea la demandada quien incorpore su prueba en primer término, cuestión que para nada altera la igualdad de las partes en el proceso, sino que únicamente materializa el mandato contenido en el artículo 1698 del Código Civil, de acuerdo al cual, será precisamente a la parte demandada, en los juicios de despido, acreditar las imputaciones efectuadas por su parte en la carta de despido; mientras que si el demandante probase primero, parecería más bien que la exigencia procesal es desvirtuar los hechos en que se funda el despido, sin que estos hayan sido previamente acreditados y sin que exista ningún tipo de presunción de veracidad que pudiere liberar a la parte demandada de esa carga procesal.

Es así que el rol del Juez en todo procedimiento laboral será interpretar y aplicar las normas propias de la materia, considerando para ello tanto los principios de la especialidad, como los principios generales del Derecho, velando especialmente por el respeto al debido proceso y garantizando a ambas partes el acceso a un Juez independiente e imparcial.

\section{EL ROL DEL JUEZ EN EL CONFLICTO COLECTIVO}

Enunciadas aquellas cuestiones previas acerca del rol del Juez en el proceso laboral, en general, corresponde analizar cómo ello se plasma, en particular, en el desarrollo del conflicto colectivo judicializado, existiendo algunas cuestiones relevantes de destacar referidas a las distintas etapas del proceso, pasando por el estudio previo de la causa, la audiencia preparatoria, la audiencia de juicio y la posterior sentencia.

Por lo pronto, por obvio que pueda parecer y en consonancia con los antes expuesto, no está de más recalcar que la primera obligación del juez será estudiar con igual atención y seriedad las alegaciones y defensas de cada parte, debiendo evitar que sus visiones personales sobre el Derecho, el mundo del trabajo u otras, lo lleven a oír sólo a una parte y a desestimar a priori a la contraria, sólo por ser tal, cuestión que no sólo se predica respecto del contenido y fundamento de la decisión, sino que también acerca de la actitud que emplea al vincularse con una y otra parte. En este sentido, cabe traer las palabras de quienes destacan como un desafío actual para el juez el inspirar confianza a través de una permanente actitud transparente, señalando que dada la crisis de legitimidad que afecta a la autoridad, especialmente en Latinoamérica -afirmación absolutamente válida en lo que respecta a nuestra administración de 
justicia, al menos según dan cuenta las diversas encuestas de opinión que año a año evalúan a distintas autoridades e instituciones nacionales y que concluyen de manera constante con el Poder Judicial ubicado en los últimos lugares de aprobación-, se hace necesario "proyectar en la sociedad la preocupación de los jueces por recuperar esa confianza estableciéndose pretenciosos estándares de conducta que van mucho más allá de lo que exige el Código Penap' ${ }^{17}$, cuestión que por cierto resulta aplicable también a nuestra especialidad.

Luego, cuando nos adentramos en la audiencia preparatoria, es claro que el respeto a ambas partes, la capacidad de oír ambas posturas, debe ser la regla. Que el Derecho del Trabajo tenga un carácter tutelar no puede significar en caso alguno que el juez se transforme en el abogado de una de las partes o en una suerte de coadyuvante de una de las partes, debiendo permitir que sean las partes las verdaderas protagonistas del proceso y no intentar guiarlo hacia cuestiones ajenas al mismo, pese a que aquellas puedan ser de gran interés jurídico o de importancia para el juez, pero, que para las partes no son el centro del conflicto.

Lo mismo podemos decir acerca de la búsqueda de soluciones colaborativas, en particular, del llamado a conciliación, si bien el Tribunal debe explorar esta vía y fijar bases, no puede subrogar, ni menos forzar la voluntad de las partes. En este orden de ideas, parece recomendable que el juez no proponga un solo esquema de solución (ajustado al modo en que cree debería concluir el proceso), sino que mantenga una actitud abierta a las distintas alternativas que a las partes les puedan parecer apropiadas a su realidad particular, con todas las complejidades que este tipo de cuestiones suele conllevar, sin manifestar tampoco su oposición a alguna solución que satisfaga a quien se presume ofendido, por estimar el Juez que aquello es insuficiente, máxime que a esas alturas del proceso, malamente puede saber si las conductas que se denuncian efectivamente ocurrieron, si lo fueron del modo que pretende la parte actora, o si la parte contará con prueba suficiente para soportar sus alegaciones.

En cuanto a la oferta de la prueba, en la misma línea sostenida a lo largo de estas páginas, cabe agregar que esta es una de las etapas en que el juez debiera hacer gala de su prudencia, ponderando las amplias facultades probatorias que el Código del Trabajo le otorga con los deberes éticos de la profesión ${ }^{18}$ y el irrestricto respeto a los derechos de ambas partes, en concreto, si bien el Código del Trabajo otorga facultades probatorias al Tribunal, no podemos perder de vista que en el proceso laboral, como ocurre con todo proceso adversarial, las cargas probatorias pesan sobre las partes, y cualquier alteración que el Juez haga en materia probatoria, aun permitida por la ley, afectará al resultado del juicio. En efecto, es perfectamente posible que cuando el Juez decreta prueba de oficio lo haga sin el afán de favorecer a una determinada parte, sino que pretendiendo alcanzar algún tipo de verdad material en relación a los hechos del juicio, en particular considerando que al decretar

\footnotetext{
17 VIGO (2007) pp. 190-191.

${ }^{18}$ Cabe anotar que en el caso de nuestro Poder Judicial, la referencia a los deberes éticos no es retórica, ya que nuestra Corte Suprema ha dictado a este respecto el Acta $N^{\circ} 262-2007$, referida a los deberes éticos funcionarios, y ha adherido al Código Iberoamericano de Ética Judicial, elaborado a partir del Estatuto del Juez Iberoamericano del año 2001, cuyo texto actual, que data del año 2014, fuera aprobado en la XVII Reunión Plenaria de la Cumbre Judicial Iberoamericana, celebrada en nuestro país. Ambos documentos se encuentran disponibles en la página web del Poder judicial: http://portal2013.pjud.cl/modulos/decalogo/decalogo_web/index.html.
} 
determinada prueba no necesariamente se conoce su contenido, pero, cualquiera que este sea, en definitiva, el resultado de esta actividad procesal afectará el resultado del juicio, por lo tanto, la actividad probatoria del juez nunca será neutra, podrá ser más o menos relevante en el resultado final del juicio, pero, la prueba que se incorpore a instancias del juez favorecerá la tesis de una u otra parte, y para la contraria, esa satisfacción de la curiosidad del juzgador, bien puede significar perder una contienda que, de no mediar esa intervención de quien no es parte en el juicio, habría ganado.

Y qué ocurre, finalmente, con la decisión del asunto, con la etapa de la sentencia. Pues bien, tal y como hemos sostenido que durante la tramitación del proceso son las partes quienes deben asumir un papel protagónico, con la misma fuerza debemos afirmar que en etapa de fallo, la situación se invierte, dado que esta es la oportunidad que la ley brinda al Juez, no sólo para resolver el caso concreto, sino que para afirmar la vigencia del derecho y aportar pautas de conducta a las partes, que sirvan de guía en sus conflictos futuros. Es en esta etapa donde el juez puede enviar mensajes de importancia vital a la sociedad, afirmando, a través de la resolución del caso concreto, cuestiones tan relevantes como si nuestro ordenamiento jurídico admite el abuso del derecho o la mala fe, por ejemplo.

En la medida que quienes ejercen la función judicial tengan claro este punto y, en consecuencia, sean rigurosos con el conocimiento y aplicación del Derecho, pronunciando decisiones consistentes y fundadas, capaces de conjurar toda sombra de arbitrariedad y discrecionalidad $^{19-20}$, las partes podrían llegar a tener bastante claridad acerca de qué conductas adoptar durante el conflicto, anticipando cómo podría ser interpretada determinada norma legal o convencional, evitándose con ellos juicios reiterativos, respecto de cuestiones ya resueltas, en los que, en ocasiones, pareciera más bien que la parte insiste en determinada cuestión hasta encontrar un Tribunal hecho a la medida de sus pretensiones.

Las ventajas de una jurisprudencia medianamente uniforme y con fundamentos contundentes son evidentes, y en lo que respecta al conflicto colectivo, ello bien podría permitir a quienes enfrentan una huelga, por ejemplo, saber hasta dónde pueden llegar las presiones o el uso de la fuerza por parte del sindicato, sin ser considerado ilegítimo o contrario a Derecho, o qué medidas puede adoptar la empresa, sin incurrir en un práctica antisindical o desleal, de tener las partes alguna claridad sobre este tipo de cuestiones, bien podría

${ }_{19}$ Acerca del rol y la relevancia de la fundamentación de las sentencias: González C., Joel, "La sana crítica y la fundamentación de las sentencias", en Actualidad jurídica, Año XVI, N 31, Enero 2015, Universidad Del Desarrollo, pp. 99 a 117.

${ }^{20} \mathrm{La}$ necesidad de fundamentar las sentencias ha sido destacada en reiteras ocasiones por los propios Tribunales Superiores, sean de Justicia o Constitucionales. Así por ejemplo, el Tribunal Constitucional Español, en STC 54/2000, analiza los requisitos que debe cumplir la sentencia a fin de satisfacer el estándar impuesto por el derecho constitucional a la tutela judicial efectiva, que dicha Carta Fundamental prevé, indica "... que uno de los variados contenidos de aquel derecho fundamental es el que se dicte una resolución fundada en derecho, motivada y razonada y no arbitraria", sentencia citada por: Malem Seña, Jorge, El error judicial y la formación de los jueces, Ed. Gedisa, Barcelona, España, 2008, p. 32; en nuestro medio, en particular en lo referido a la materia laboral y al cumplimiento del estándar que fijan las reglas de ponderación de conformidad a la sana crítica, se pronuncia la sentencia dictada por la Excma. Corte Suprema con fecha 14 de abril de 2015, que acogió el Recurso de Unificación de Jurisprudencia Rol N²2.339-14. 
facilitárseles la búsqueda de soluciones autocompositivas y disminuir los incentivos al litigio y los costos que ello conlleva, tanto para las partes como para el propio sistema judicial.

Finalmente, y en relación a la oportunidad de la intervención judicial, cabe hacer presente que suele comentarse que el Derecho llega tarde, afirmando que cuando el Tribunal conoce del asunto, en particular, cuando se dicta la sentencia, las conductas cuestionadas ya se han producido, de modo que de existir alguna vulneración a la libertad sindical sus efectos ya se han radicado en la organización o en los trabajadores afectados y bien puede ser que, por la naturaleza de los hechos, la sentencia no logre el efecto de retrotraer las cosas a su estado previo a la vulneración y que las sanciones que en su caso se apliquen, incluso sean gustosamente asumidas por la parte que ya ha logrado el fin buscado mediante dichas infracciones, como puede ser el impedir la constitución de un sindicato o el desarticular uno existente $^{21}$.

Sin embargo, cuando se efectúan afirmaciones como aquellas, no puede perderse de vista que luego de las modificaciones introducidas al procedimiento laboral mediante la ley 20.022 (D.O. 30.05.05), uno de los aspectos que ha mejorado a favor de las partes que concurren ante los Juzgado de Letras del Trabajo es, precisamente, la oportunidad con que el Juez personalmente toma conocimientos de los hechos y a partir de la cual puede actuar a fin de evitar la consolidación de situaciones perjudiciales para la parte demandante. En efecto, sabido es para quienes tramitaron en el marco del antiguo procedimiento laboral que la regla general era que toda la tramitación fuera mediada por los funcionarios del Tribunal, de modo que cuando el Juez realmente conocía y estudiaba los hechos, era al momento de dictar la sentencia, lo que bien podía ocurrir años después de interpuesta la denuncia o demanda. Hoy la situación es diametralmente distinta, dado que no sólo se establecen como principios formativos del proceso la celeridad y el impulso procesal de oficio, que redundan en una mayor rapidez de la tramitación, sino que también la inmediación, lo que supone que el Juez, ya desde la presentación de la demanda y aún con mayor intensidad durante las respectivas audiencias, toma directo conocimiento de las alegaciones y defensas de las partes, contando de conformidad con el artículo 492 del Código del Trabajo, con facultades para disponer de oficio o a petición de parte, en la primera resolución que dicte en el proceso la suspensión de los efectos del acto impugnado, bajo apercibimiento de multa y sin que proceda recurso alguno en contra de esa resolución.

Así las cosas, en el actual procedimiento, no sólo el proceso es más rápido, sino que se otorgan al Juez amplias facultades para adoptar, de oficio o a petición de parte, desde la

\footnotetext{
${ }^{21}$ En ese sentido se pronuncia, por ejemplo, el considerando décimo sexto de la sentencia dictada con fecha 10 de enero de 2013, por el Juzgado de Letras del Trabajo de la Serena en la causa RIT T-20-2012. Afirmaciones a las que ha adherido, incluso, el Sr. Presidente de la Excma. Corte Suprema, al citar dicha sentencia en un seminario titulado "Los derechos fundamentales y la eficacia directa en el derecho laboral nacional: la experiencia italiana y chilena", celebrado en dicho Tribunal el 28 de julio de 2015. Expresiones que fueron registradas en distintas notas de prensa, como ocurrió, entre otros, con los diarios electrónico El Mostrador, http://www.elmostrador.cl/noticias/pais/2015/07/30/presidente-de-la-suprema-hace-crudo-diagnostico-de-larealidad-laboral-en-chile-y-critica-esquema-neoliberal-que-la-rige,$\quad$ o Diario Judicial http://www.diariojudicial.net/2015/07/30/los-cuestionamientos-al-r\%C3\%A9gimen-laboral-que-realizaronministros-mu $\% \mathrm{C} 3 \% \mathrm{~B} 1 \mathrm{oz}-\mathrm{y}$-cerda/.
} 
interposición de la demanda, medidas cautelares que impidan la consolidación de los efectos de los actos objeto de impugnación. De modo que si bien sigue siendo posible que en ocasiones la sentencia no haga una diferencia en el caso concreto o que la decisión choque con la voluntad de una parte absolutamente refractaria, al menos, debemos reconocer que las condiciones procesales actuales son bastante más favorables que aquellas existentes durante la vigencia del antiguo procedimiento o el algunos países vecinos, donde este tipo de procedimientos siguen siendo conocidos mediante procedimientos escritos que no consagran la inmediación, por lo que en nuestro actual sistema procesal laboral, una petición efectuada a tiempo puede hacer mucho en orden a evitar que las consecuencias dañosas del actor se transformen en permanentes.

\section{LA JUDICATURA LABORAL Y EL PROYECTO DE REFORMA AL SISTEMA DE RELACIONES LABORALES}

El Proyecto de Reforma, actualmente en tramitación, sin duda afectará el modo en que los Jueces del Trabajo adoptan sus decisiones, al modificar la norma que debe estos deben aplicar, sin embargo, la relación entre la judicatura laboral y este proyecto en particular, no sólo se proyecta hacia el futuro, sino que ya, hay una serie de cuestiones que forman parte del Proyecto, sea en mérito de su texto original o de las indicaciones posteriores, que son objeto de pronunciamiento laboral, sin perjuicio que el contenido de dichos pronunciamientos pueda variar luego, en el evento que el legislador prefiera avanzar en un sentido distinto.

Algunas de las cuestiones contenidas en el Proyecto y que ya son objeto de análisis judicial son los límites de la huelga, en relación a si ella debe ser pacífica, como lo sostenía el Proyecto en su texto inicial; también se han pronunciado distintas sentencias que han avanzado, en materia de reemplazo, en un sentido similar al que hoy se debate por parte de los actores políticos; lo mismo que ocurre acerca de los alcances de la buena fue durante la negociación colectiva y la huelga. Aspectos a los cuales nos referiremos a continuación.

Respecto a la huelga, tenemos que si bien ha sido regulada tanto en la Constitución Política como en el Código del Trabajo, nuestro legislador nacional no la ha definido. La Comisión Ortúzar debatió en su oportunidad acerca de si se trataba de un hecho de relevancia jurídica o de un derecho propiamente tal, tesis esta última a la que adherimos según hemos expresado en trabajos previos ${ }^{22}$, pero, ni en la Constitución, ni en el Código del Trabajo se le definió o se aportaron elementos que permitan precisar los confines de este derecho.

El Proyecto en análisis, en su texto inicial, señalaba en el artículo 349 propuesto que "La buelga es un derecho que debe ser ejercido colectiva y pacificamente por los trabajadores", calificativo, el

\footnotetext{
22 Para más detalles acerca de este debate y la conclusión de la autora al respecto, ver: Fuenzalida Martínez, Patricia, "Reconocimiento y protección constitucional de la huelga en España y Chile: un análisis comparado", en Revista de Derecho Laboraly Seguridad Social, Volumen II, N³, Año 2014, Ed. Thompson Reuters, pp. 21-48.
} 
de pacífica, que ha sido objeto de intenso debate y que fuera eliminado del Proyecto. No obstante, quienes criticaban esta conceptualización de la huelga aparentemente olvidan que la huelga, como todo derecho, tiene límites, no pudiendo servir de excusa para la afectación ilegítima, desproporcionada o innecesaria de otros derechos de terceros, así como su carácter autotutelar no puede ser entendido como una carta abierta frente a acciones violentas; olvidando asimismo que nuestro sistema no es el único en que se plantean discusiones referidas a los límites o márgenes del ejercicio de la huelga, así por ejemplo, en la legislación española encontramos el concepto de huelga abusiva, definida como aquella en que se origina un daño a la empresa, siempre que "el daño sea grave y que haya sido buscado por los huelguistas más allá de lo que es razonablemente requerido por la propia actividad conflictiva y por las exigencias inherentes a la presión que la buelga necesariamente implica" 23 , en tanto que la legislación francesa también permite al juez precisar los límites de tal derecho, sea distinguiendo entre acciones colectivas que son huelga de aquellas que no lo son, o analizando, como en el caso español, si el ejercicio concreto de la huelga es legítimo o puede ser calificado de abusivo ${ }^{24}$.

Y ¿cómo es que nuestros Tribunales se han pronunciado acerca del carácter pacífico o no de la huelga, a falta de norma que así lo disponga expresamente? Lo hacen cada vez que conocen de un desafuero sindical o de un despido de un trabajador no aforado, cuando el sustento fáctico del despido se refiere a las conductas que aquel ha desplegado durante una huelga propiamente tal o durante algún tipo de movilización dentro de la empresa ajena al contexto de la negociación colectiva, casos en que los Tribunales han tenido la posibilidad de ir configurando los límites o los contornos de este derecho, al tener que ir determinando si la circunstancia de haber ocurrido el hecho durante una huelga exime al trabajador de cualquier cumplimiento mínimo de obligaciones para con su empleador o si, por ejemplo, una movilización ocurrida fuera del contexto de la negociación colectiva puede contar con el amparo conferido a la huelga.

Precisemos lo anterior con un ejemplo, si un trabajador es despedido o se solicita su desafuero por pararse junto a su puesto de trabajo y no hacer nada, pero, añade el empleador que aquello ocurrió durante una huelga de la cual este trabajador formaba parte, probable será sencillo concordar que la conducta de ese trabajador no es antijurídica o ilegítima, sino que por el contario, estaba amparada por el ejercicio del derecho a huelga; luego, si este trabajador es despedido o se solicita su desafuero por estar fuera de la empresa con carteles, de manera ruidosa, intentando alejar al público o a los trabajadores que no han tomado parte en la huelga, nos encontraremos en una zona algo más gris, seguramente algunos estimarán que aquello sigue siendo parte del legítimo ejercicio del derecho, quizás otros estimarán que los desórdenes en la vía pública exceden de dicho ejercicio legítimo del derecho, cuestión que nos llevará a ponderar, de acuerdo a las circunstancias precisas del caso, qué derecho debe primar en esa situación concreta; pero, si extremamos el ejemplo, y pensamos que ese trabajador, siempre durante la huelga, agrede físicamente a un compañero que intenta entrar a prestar sus servicios, o destruye intencionalmente bienes de la empresa, entonces sería bastante más difícil sostener que seguimos estando frente al legítimo ejercicio de un derecho o que tales conductas forman parte de su derecho a huelga.

\footnotetext{
${ }^{23}$ BAYLOS (2009) p. 67.

${ }^{24}$ SUPIOT (2008) p. 97.
} 
Por cierto que los jueces, actualmente, sostienen este tipo de discusiones en sus sentencias, siendo necesario que lo hagan, ya que si en un caso como los propuestos previamente el Tribunal se negara a analizar la conducta del trabajador, sosteniendo por ejemplo que durante la huelga la relación laboral se suspende y que por tanto no cabe exigencia de ningún tipo de deber, como el deber de lealtad del que se puede derivar la exigencia de no destruir las herramientas de trabajo que serán necesarias concluida la huelga, bien podría considerarse que ese Juez está vulnerando la inexcusabilidad consagrada en la Constitución, incurriendo en una denegación de justicia y, más grave aún por sus consecuencias prácticas, estaría declarando a la huelga como un especio ubicado fuera de los límites del Derecho, donde la única ley vigente sería la del más fuerte.

Del mismo modo, en el proyecto inicial, la buena fe tenía un rol fundamental, así se destacaba en el mensaje que precedía al proyecto, el que también contenía una serie de normas que invocaban este principio. Así por ejemplo, el artículo 411 letra a), declaraba como práctica desleal del empleador: "La ejecución durante el proceso de la negociación colectiva de acciones que impliquen una vulneración al principio de buena fe que afecte el normal desarrollo de la misma"; seguido de ello, la letra a) del artículo 412 propuesto, declaraba como prácticas desleales del trabajador, de las organizaciones sindicales o de éstos y del empleador en su caso: "La ejecución durante el proceso de la negociación colectiva de acciones que impliquen una vulneración al principio de buena fe que afecte el normal desarrollo de la misma".

En este punto también ciertos sectores de la academia y del quehacer político han cuestionado que se exija, en particular respecto del sindicato, una actuación de buena fe en una situación de conflicto ${ }^{25}$, sin embargo, esta es una exigencia que los Tribunales del Trabajo ya han impuesto a una y otra parte, bastando como ejemplo de aquello con mencionar los numerosos casos en que se ha privado de la protección que otorga el fuero a un trabajador respecto de quien se acreditó que había abusado del ejercicio de ese derecho, esto es, que se ha premunido de la calidad de dirigente sindical, no para buscar mejores condiciones laborales para sus compañeros de trabajo, sino únicamente para enervar una decisión de la empresa. En efecto, tan común se ha vuelto este examen exhaustivo del modo en que se ha adquirido el fuero, por parte de la judicatura, sobre todo en casos de sindicatos constituidos en forma coetánea con la decisión de despido, que esta línea de decisiones ha llevado incluso a crear un término específico que describe la situación, cual es, la expresión "sindicato del día después".

Otro tanto se puede decir respecto del reemplazo, en que el artículo 349 inciso segundo propuesto señala: "Se prohíbe el reemplazo de los puestos de trabajo de los trabajadores en huelga. La infracción de esta probibición constituye una práctica desleal grave, habilitando a la Inspección del Trabajo para requerir el retiro inmediato de los trabajadores reemplazantes de los puestos de trabajo en huelga", vale decir, el Proyecto proponía, pura y simplemente, el reemplazo de los puestos de trabajo de quienes tomasen parte en la huelga, sin perjuicio que en el estado actual de la discusión se hayan introducido igualmente indicaciones tendientes a permitir la reasignación interna de funciones, en caso de cumplirse determinados requisitos.

${ }^{25}$ Ver nota 10. 
Dicho debate parlamentario, entre el proyecto inicial y las indicaciones posteriores, remite a aquella discusión en la que desde algún tiempo han tomado parte Tribunales y doctrina, por cuanto lo que nuestro actual artículo 381 del Código del Trabajo declara que se prohíbe "el reemplazo de los trabajadores en buelga...", salvo que el empleador cumpla con los requisitos allí previstos, caso en que “... el empleador podrá contratar a los trabajadores que considere necesarios para el desempeño de las funciones de los involucrados en la buelga, a partir del primer día de haberse hecho ésta efectiva". Es así que la voz "contratar" contenida en la norma actualmente en vigencia, también ha llevado a toda una discusión jurisprudencial que, mucho antes de la prohibición de reemplazo más estricta que hoy se propone, ha analizado si lo que el empleador no puede hacer, salvo que cumpla con los requisitos indicados en la norma es únicamente celebrar nuevos contratos de trabajo a fin de reemplazar a estos trabajadores, o si también se ve impedido de modificar las funciones de otros trabajadores, que ya forman parte de la empresa y que no han participado en la huelga, a fin de que estos desarrollen tanto sus funciones como las de los trabajadores en huelga, lo que también ha dado origen a otros nuevos conceptos que hoy forman parte del debate, distinguiéndose entre reemplazo interno (modificación de funciones) y reemplazo externo (contratación propiamente tal) de trabajadores. Siendo la tesis hoy actualmente en vigencia aquella que, en concordancia con el contenido al menos inicial del Proyecto, entiende que lo prohibido es el "reemplazo interno", esto es, que no se puede reemplazar el puesto de trabajo, aún con trabajadores que ya realizaban otras labores en forma previa en la empresa, fueren estas similares o no a aquellas a reemplazar, estimando esta línea jurisprudencial que esta interpretación de carácter teleológica, elevaría el estándar de protección a la libertad sindical y del derecho a huelga ${ }^{26}$.

Es así como vemos que algunos aspectos relevantes contenidos en el proyecto son ya objeto de atención judicial, mediante decisiones que, aprobado que sea el proyecto en trámite, deberán ser revisadas a la luz de la nueva normativa, a fin de incorporar su contenido a la fundamentación de tales decisiones; y en caso de no resultar acordes los actuales criterios jurisprudenciales con el contenido de aquella, estos deberán ser modificados, adecuándose al sentido perseguido por la ley, en tanto expresión de la voluntad popular. En tanto que existirán otros tantos aspectos nuevos, referidos a materias que, de ser incorporados a la legislación laboral por el proyecto, vendrán a modificar y/o a ampliar las competencias actuales de los Tribunales del Trabajo, como ocurre con los reclamos que se pudieren originar respecto de la determinación y cumplimiento de los servicios mínimos y equipos de emergencia o las cuestiones que pudieren derivar del cumplimiento y aplicación de los pactos sobre condiciones especiales de trabajo, entre otras.

${ }^{26}$ Como ejemplo de esta línea jurisprudencial, podemos citar las sentencias dictadas por la Excma. Corte Suprema, en Recursos de Unificación de Jurisprudencia Rol N 3514-2014, sentencia de 4 de diciembre de 2014; Rol N 10.444- 2014 sentencia de 29 de enero de 2015; y Rol N 15.293-2014, sentencia de 12 de mayo de 2015. 


\section{CONCLUSIONES}

Como hemos puesto de relieve en las páginas precedentes, sea en el marco de nuestro actual sistema de relaciones laborales o en aquel nuevo sistema que sea inaugurado con la aprobación del proyecto de ley en trámite, es imposible desconocer que los Tribunales del Trabajo cumplen un importante rol consistente en afirmar la vigencia de la ley y precisar su contenido, cuestión que parece ser especialmente cierta en materia de Derecho Colectivo, en que la cantidad de derechos individuales y colectivos en conflicto, y las complejidades y particularidades de cada proceso de negociación, llevan a que el legislador muchas veces opte por normas más bien amplias, en que será el juez quien deberá precisar el contenido del derecho en el caso concreto, como ocurre también en otras legislaciones ${ }^{27}$.

Hemos dicho también como esta importante labor del Juez, le exige que despliegue todos sus esfuerzos personales y profesionales, a fin de arribar a una decisión correcta, que pueda ir generando una jurisprudencia constante y fundada, dado que ello contribuye a la certeza jurídica, la que a su vez, podrá guiar el actuar de las partes en el futuro, además de aportar elementos sobre los cuales las partes por sí solas o con la ayuda de terceros, en proceso de conciliación, mediación o arbitraje, puedan construir la solución a sus conflictos antes de recurrir a una judicialización que pueda causarles perjuicios tanto en términos de tiempo y dinero, como en cuanto a afectar las confianzas sobre las cuales se asentará el cumplimiento de los acuerdos que se adopten.

La tarea antes descrita, no es sencilla, ya que como hemos mencionado, en nuestra especialidad, el Juez debe compatibilizar su función tutelar del trabajador con la función tutelar respecto del propio Derecho y sus principios generales, sin embargo, si logra sortear con éxito tal dificultad, podrá ir construyendo decisiones que se conviertan en un camino destinado a ser luego transitado por las partes en el desarrollo de sus conflictos, de modo de buscar la profundización de la libertad sindical y las mejoras de las condiciones de trabajo de los trabajadores, mediante acciones que reflejen, de una y otra parte, además, una búsqueda de paz y justicia social, transformando al conflicto colectivo, desde un conflicto de suma cero a uno de tipo colaborativo, a una oportunidad de encuentro entre quienes, por su conocimiento directo de la empresa y su realidad, están en las mejores condiciones para avanzar hacia lo que debe ser necesariamente un fin común, una empresa viable y productiva, que asegure el sustento a todos quienes forman parte de ella, sea como dueños o directivos de las mismas o como trabajadores, y que además les de amplias posibilidades de desarrollo personal y profesional.

Principios que, es de esperar, guíen tanto a quien debe resolver un conflicto jurídico colectivo, como al legislador, de modo que tras el extenso debate que se ha generado durante la tramitación del proyecto, se ofrezca un cuerpo normativo que sea aplicable, desde su punto de vista práctico; que no cree trabas innecesarias al proceso colectivo, sea en su vertiente judicial o

${ }^{27}$ Ver notas 23 y 24. 
Patricia Fuenzalida Martínez / Judicialización del conflicto colectivo y el rol del juez en su solución

extrajudicial; cuyos alcances y sentido sean medianamente claros para todos los involucrados; y que no suponga desequilibrios excesivos o ilegítimos entre las partes, sino que siente las bases para el desarrollo de relaciones entre las partes en términos de igualdad y colaboración, susceptibles de extenderse, más allá de la sola elaboración del contrato colectivo, durante todo su período de vigencia. 


\section{BIBLIOGRAFÍA}

BAYLOS GRAU, Antonio (2004): Sindicalismo y derecho sindical. (España, Editorial Bomarzo, cuarta edición).

FUENZALIDA MARTÍNEZ, Patricia (2014): "Reconocimiento y protección constitucional de la huelga en España y Chile: un análisis comparado", Revista de Derecho Laboral y Seguridad Social, Vol. II, N³, pp. 21-48.

GONZALEZ CASTILLO, Joel (2015):” La sana crítica y la fundamentación de las sentencias", Actualidad jurídica, Año XVI, N 31, pp. 99 - 117.

IBÀÑEZ, Perfecto Andrés (2011): Cultura constitucional de la jurisdicción. (Bogotá, Editorial Siglo del Hombre)

MALEM SEÑA, Jorge (2008): El error judicial y la formación de los jueces. (Barcelona, Editorial Gedisa).

MARTÍNEZ RIVERA, Jorge (2015), "Reforma laboral, la peor de todas", El Libero. Disponible en: http://ellibero.cl/ideas-libres/reforma-laboral-la-peor-de-todas/.

MORGADO VALENZUELA, Emilio (1998): "Necesidad, funcionalidad y viabilidad de la negociación colectiva en el marco de los actuales procesos de cambios: La situación en Chile", en: Estudios en homenaje al profesor William Thayer (Santiago, Sociedad Chilena de Derecho del Trabajo y de la Seguridad Social).pp. $162-180$.

PALAVECINO CÁCERES, Claudio (2015), "Mayor protagonismo de la dirección del trabajo trae el riesgo que el conflicto colectivo se politice", Estrategia on line. Disponible, http://www.estrategia.cl/noticias/detalle/ultimo-minuto-portada/110993/mayor-

protagonismo-de-la-direccion-del-trabajo-trae-el-riesgo-que-el-conflicto-colectivo-se-politice.

RUAY SÁEZ, Francisco (2014): “Análisis crítico de las potestades atípicas del juez laboral ante el principio de juridicidad", Revista chilena de derecho del trabajo y de la seguridad social, Vol. 5, $\mathrm{N}^{\circ}$ 9, pp. 83-105.

SOTO KLOSS, Eduardo (1996): Derecho administrativo, bases fundamentales, Tomo II. (Santiago, Chile, Editorial Jurídica de Chile). 
SUPIOT, Alain (2008): Derecho del trabajo. (Buenos Aires, Editorial Heliasta).

THAYER ARTEAGA, William (2010). "Utilidad de la huelga. Aproximación a un estudio sobre sus expectativas y costos", Revista chilena de derecho del trabajo y de la seguridad social, Vol. 1, $\mathrm{N}^{\circ} 2$, pp. 199-211.

VIGO, Rodolfo (2007): Ética y responsabilidad judicial. (Buenos Aires, Editorial Rubinzal Culzoni).

CAAMAÑO ROJO, Eduardo (2015), "Los nuevos carceleros de la libertad sindical", El Mostrador. Dsiponible en http://www.elmostrador.cl/noticias/opinion/2015/07/31/losnuevos-carceleros-de-la-libertad-sindical/.

UGARTE CATALDO, José Luis (2015), "El senador Lagos Weber y la OIT ‘a la carta”, El Mostrador, Disponible en: http://www.elmostrador.cl/noticias/opinion/2015/07/07/elsenador-lagos-weber-y-la-oit-a-la-carta/. 